\title{
KONFIRMASI DAM EFFECT PADA SIFAT BERAT LAHIR SILANGAN KAMBING BOER
}

\author{
Sigit Prastowo, Tristianto Nugroho, Atik Nurhidayati dan Nuzul Widyas* \\ Program Studi Peternakan, Universitas Sebelas Maret. \\ Jl. Ir. Sutami 36A, Surakarta. *Corresponding author: nuzul.widyas@staff.uns.ac.id
}

\begin{abstract}
Abstrak
Dam effect merupakan pengaruh induk yang terkait dengan kemampuan induk untuk mendukung kebuntingan, produksi susu, dan kemampuan merawat anak dari lahir sampai masa sapih. Peranan dam effect adalah mendukung pertumbuhan awal anak. Penelitian ini bertujuan untuk mengkonfirmasi adanya dam effect pada sifat berat lahir (BL) pada silangan kambing Boer. Materi yang digunakan berupa data recording BL dari 1001 ekor anak kambing di CV. Kambing Burja, Batu, Jawa Timur dari tahun 20122016. Untuk mengetahui adanya dam effect, analisis data dilakukan dengan membandingkan dua model Analysis of Variance (ANOVA) yang berbeda. Model pertama (Model 1) disebut dengan reduced model karena faktor dam tidak digunakan dalam perhitungan, sementara model kedua (Model 2) disebut complete model karena faktor dam digunakan sebagai random effect. Pejantan, komposisi darah induk, paritas induk, jenis kelamin anak, tipe kelahiran dan tahun pengamatan digunakan sebagai fixed effect untuk kedua model tersebut. Konfirmasi adanya dam effect dilakukan dengan membandingkan kedua model menggunakan $F$ test for overall significance. Hasil analisis menunjukkan bahwa BL tidak dipengaruhi $(p>0,05)$ oleh faktor komposisi darah induk, akan tetapi secara nyata $(p<0,05)$ dipengaruhi oleh pejantan, paritas induk, jenis kelamin, tipe kelahiran dan tahun pengamatan. Pada perbandingan Model 1 dan Model 2 untuk sifat BL diperoleh perbedaan yang nyata $(P<0,05)$. Selanjutnya dapat disimpulkan dam effect memengaruhi sifat $B L$, sehingga faktor induk menjadi perlu dipertimbangkan dalam proses seleksi.
\end{abstract}

Kata kunci: dam effect, berat lahir, silangan kambing Boer

\begin{abstract}
Dam effect is the ability affecting pregnancy, milk production, and the ability to care for kiduntil the weaning period. The role of the dam effect is to support the child's early growth. This study aims to confirm the dam effect on the birth weight of Boer goat crosses in CV. Kambing Burja, Batu, East Java. The material used in this research is data records of birth weight including identity of parent, parity of dam, sex of kids, birth type, and birth date. Total number of observations were 1001 individuals was collected from 2012 until 2016. Dam effect confirmation was done by comparing two different statistical models each with and without dam effect. Bucks factor, dam breed composition, parity of dam, sex of kids, birth type and observation year were used as fixed effects for both models. Model 1 was analyzed by ANOVA while Model 2 was analyzed by mixed model. Both models were compared using F-test of overall significance.Based on Model 2 analysis result, it was known that bucks factor, parity of dam, birth type, sex and observation year have an effect on birth weight. The results of Model 1 and Model 2 comparison showed that there were significant differences $(P<0,05)$. This indicates there was dam effect on the birth weight. It can be explained that dam as individual indeed held influences on the birth weightof their offspring.
\end{abstract}

Keywords: dam effect, birth weight, Boer goat crosses

\section{PENDAHULUAN}

Kambing Boer merupakan kambing tipe pedaging yang berkembang di Afrika Selatan(Devandra \& Burns, 1994). Kambing Boer memiliki keunggulan mudah beradaptasi pada berbagai kondisi lingkungan, kualitas karkas dan konformasi tubuh yang bagusserta pertumbuhan yang cepat (Casey dan Van Niekerk, 1988). Persilangan kambing Boer galur murni (pure breed) dengan kambing lokal dapat meningkatkan produktivitas kambing lokal. Sebagai contoh, persilangan kambing Boer dengan Kacang memberikan peningkatan berat lahir (BL) sebesar 32\% (Elieser et al., 2006), sedangkan pada persilangan kambing Boer dengan Peranakan Etawa meningkatkan $\mathrm{BL}$ sebesar $15,6 \%$ (Kostaman dan Sutama, 2005). Disebutkan lebih lanjut bahwa mutu keturunan persilangan persilangan dapat ditingkatkan 
dengan program pemuliaan melalui seleksi pejantan berdasarkan performa dari keturunan yang telah dihasilkan (Hardjosubroto, 1994). Performa sifat pertumbuhan keturunan seperti BL dalam hal ini dapat digunakan sebagai kriteria seleksi.

Sifat $\mathrm{BL}$ pada kambing tidak hanya dipengaruhi oleh potensi genetik dirinya sendiri, akan tetapi juga dipengaruhi oleh pengaruh induk atau dam effect (Szwaczkowskiet al., 2006; Van Niekerk et al., 1996). Dam effectmerupakan pengaruh induk yang tidak terkait dengan genetik yang diturunkan langsung (direct effect) (Szwaczkowski et al., 2006), tetapi diwujudkan melalui kemampuan induk dalam mendukung keadaan kebuntingan yang baik, kemampuan produksi susu pasca melahirkan dan kemampuan merawat anak (Bradford, 1972). Zhang et al. (2008) menyatakan dam effect berperan penting dalam sifat pertumbuhan awal. Dijelaskan bahwa dam effect berpengaruh besar terhadap $\mathrm{BL}$ anak (Szwaczkowski et al., 2006; Van Niekerk et al., 1996) karena berkaitan dengan kemampuan induk dalam menyediakan lingkungan uterus yang baik selama masa kebuntingan. Pengaruh dam effect akan berlanjut sampai dengan masa sapih (Praharani, 2007; Meyer, 1992) karena tergantung dari kemampuan dalam merawat anak serta memproduksi susu danakan mulai hilang pasca sapih (Mandal, Neser, Rout, Roy, \& Notter, 2006). Untuk itulah, evaluasi genetik dalam proses seleksi sebaiknya menyertakan pengaruh induk (Al-Shorepy et al., 2002; Robison, 1981; Szwaczkowski et al., 2006; Zhang et al., 2008) karena peniadaan pengaruh tersebut akan membuat bias dalam perhitungan ragam genetik sifat pertumbuhan BL ternak (Van Niekerk et al., 1996).

Berdasarkan informasi tersebut, maka penelitian ini bertujuan untuk mengkonfirmasi adanya dam effect pada sifat BL silangan kambing Boer. Hasil penelitian ini diharapkan bermanfaat untuk pelaksanaan manajemen breeding pada kambing Boer dan silangannya. Informasi tentang dam effect akan menjadi pertimbangan untuk seleksi pejantan yang lebih akurat.

\section{METODE PENELITIAN}

\subsection{Tempat dan Waktu Penelitian}

Penelitian ini dilaksanakan pada bulan Januari sampai April 2017. Pengambilan data dilaksanakan di CV. Kambing Burja, Batu, Jawa Timur.

\subsection{Materi}

Materi yang digunakan dalam penelitian ini adalah data recording di CV. Kambing Burja mulai tahun 2012 sampai dengan 2016.

\subsection{Metode}

\subsubsection{Koleksi Data}

Data kelahiran sebanyak 5735 dari 30 pejantan dan 1792 induk dicatat mulai dari bulan Januari 2012 sampai dengan bulan Juni 2016. Data tersebut merupakan data kasar yang perlu dilakukan quality control dengan cara memeriksa kelengkapan data. Data yang dianalisis harus memiliki informasi berupa identitas ternak, informasi tetua, paritas induk, jenis kelamin anak, tipe kelahiran, tanggal kelahiran dan BL. Setelah dilakukan quality control didapatkan data BL sebanyak 1081 yang berasal dari 16 pejantan dan 527 induk.

Identitas 16 pejantan Boer yang digunakan dalam penelitian ini yaitu Adam0161 (AD), Brett1077 (BR), Cecil0411 (CC), Cecil Junior008 (CC Jr), Chata0187 $(\mathrm{CH})$, Chata Junior $006(\mathrm{CH} \mathrm{Jr})$, Chester Junior 047(CS Jr), Debonair 0602 (DA), Ernie 0196 (ER), Ernie Junior 012 (ER Jr), Guardian 1105 (GD), Guardian Junior 071 (GD Jr), Rocky 0351 (RO), Songstar 0037 (SO), Terje 0124 (TR) dan Winora FBKB001 (WR). Sedangkan induk betina yang berjumlah 527 individu memiliki komposisi darah 50\% Boer (F1), 75\% Boer (F2) dan 100\% Boer dengan paritas 1, 2 dan 3. Untuk paritas dihitung dengan melihat catatan kelahirannya. Tipe kelahiran dikategorikan tipe tunggal dan kembar $(\geq 2)$ dengan jenis kelamin anak jantan dan betina, dimana data kelahirandiambil pada tahun 2013, 2014, 2015 dan 2016.

Menurut (Devandra \& Burns, 1994), penimbangan $\mathrm{BL}$ sebaiknya dilakukan dalam 
waktu 12 jam sejak lahir untuk memperoleh catatan yang cermat.

\subsubsection{Analisis Data}

Konfirmasi adanya dam effect pada silangan kambing Boer dilakukan dengan membandingkan dua model Analysis of Variance (ANOVA) yaitu dengan dan tanpa menambahkan faktor induk (dam). Model pertama (Model 1) yang kemudian disebut dengan reduced model dimana dalam model ini tidak ditambahkan faktor dam dalam perhitungan. Sementara model kedua (Model 2) disebut dengan complete model dimana faktor dam digunakan sebagai random effect. Faktor pejantan, komposisi darah induk, paritas induk, jenis kelamin anak, tipe kelahiran dan tahun pengamatan digunakan sebagai faktor tetap (fixed effect) dalam kedua model analisis.

Model statistik yang digunakan untuk analisis adalah sebagai berikut:

Model 1: $1=\mu+P j t n+K D+$ Par+ Tipe+ JK + Thn $+e$

Model 2: $\mathrm{Y}=\mu+$ Pjtn+ KD + Par + Tipe + JK + Thn+Dam+e

Keterangan :

$\mathrm{Y} \quad=$ respon variabel $(\mathrm{BL})$

$\mu \quad=$ nilai tengah umum

Pjtn = pejantan $(A D, B R, C C, C C \mathrm{Jr}, \mathrm{CH}$, $\mathrm{CH} \mathrm{Jr}$, CS Jr, DA, ER, ER Jr, GD, GD $\mathrm{Jr}, \mathrm{RO}, \mathrm{SO}, \mathrm{TR}$ dan WR)

$\mathrm{KD}=$ komposisi darah induk $(50 \%$ Boer (F1), $75 \%$ Boer (F2) dan 100\% Boer)

Par = paritas induk (1, 2 dan 3$)$

Tipe = tipe kelahiran (tunggal dan kembar $(\geq 2)$ )

$\mathrm{JK}=$ jenis kelamin anak (jantan dan betina)

Tahun $=$ tahun pengamatan $(2013,2014$, 2015 dan 2016)

Dam = individu induk

e $\quad=$ random error

Analisis data dilakukan dengan menggunakan custom script yang ditulis dengan $R$ programming language. Kedua model kemudian dibandingkan dengan menggunakan prosedur F-test of overall significance (Ott \& Longnecker, 2010). Nilai Mean Square Error (MSE) kedua model dibandingkan dengan menggunakan nilai alpha 0,05untuk mengevaluasi perbedaan model.

\section{HASIL DAN PEMBAHASAN}

\subsection{Pengaruh Fixed Effect terhadap Berat} Lahir

Signifikansi fixed effect dari Model 2 disajikan dalam Tabel 1, sedangkan tabulasi faktor, jumlah data, rerata dan standar deviasi BL disajikan dalam Tabel 2. Berdasarkan hasil analisis diketahui bahwa hasil perhitungan Model 2 (Tabel 1), faktor yang memengaruhi BL selain faktor dam ialah faktor pejantan, paritas induk, tipe kelahiran, jenis kelamin serta tahun pengamatan.

Tabel 1. Signifikansi fixed effect terhadap BL

\begin{tabular}{|c|c|c|}
\hline Faktor & Level & $\frac{\text { Nilai } P}{B L}$ \\
\hline \multirow{2}{*}{$\begin{array}{l}\text { Pejantan } \\
\text { Komposisi darah } \\
\text { induk }\end{array}$} & \multirow{2}{*}{$\begin{array}{c}16 \\
2\end{array}$} & 0,016 \\
\hline & & 0,471 \\
\hline Paritas & 3 & $<0,001$ \\
\hline Tipe kelahiran & 2 & $<0,001$ \\
\hline Jenis kelamin & 2 & $<0,001$ \\
\hline $\begin{array}{l}\text { Tahun } \\
\text { pengamatan }\end{array}$ & 4 & $<0,001$ \\
\hline $\begin{array}{l}\text { Keterangan: } \\
\text { ditunjukkan deng }\end{array}$ & aits & perbedaan \\
\hline
\end{tabular}

Hardjosubroto (1994) menyatakan bahwa performa keturunan dipengaruhi oleh faktor genetik yang diwariskan oleh tetuanya. Dalam hal ini pejantan memberikan pengaruh besar tehadap potensi genetik keturunan dalam performa BL. Nurgiartiningsih (2011) melaporkan bahwa keturunan dari galur pejantan yang berbeda akan mempunyai BL yang berbeda pula. Pengaruh pejantan akan menunjukkan perbedaan genetik untuk tumbuh (Warwick, Astuti, \& Hardjosubroto, 1990), karena setiap pejantan mempunyai potensi yang berbeda-beda sehingga pengaruhnya terhadap anak juga bervariasi.

Paritas induk memengaruhi BL. Berdasarkan Tabel 2, induk dengan paritas kedua dan ketiga memiliki anak dengan $\mathrm{BL}$ paling tinggi. Zhang et al. (2008) 
menyebutkan bahwa paritas induk berpengaruh pada $\mathrm{BL}$ anak. Hal tersebut dapat dijelaskan dengan berkembangnya uterus seiring dengan bertambahnya paritas dan juga umur induk.

Tipe kelahiran berpengaruh pada $\mathrm{BL}$ dimana tipe kelahiran tunggal memiliki $B L$ yang lebih tinggi dibandingkan dengan kelahiran kembar (Tabel 2). Hal tersebut sesuai dengan yang dilaporkan oleh Mahmalia et al. (2010) dan Elieser et al. (2004). Anak yang dilahirkan tunggal memiliki $\mathrm{BL}$ yang lebih tinggi karena tidak adanya kompetisi antar anak dalam mendapatkan asupan makanan selama di dalam uterus.

Berat lahir keturunan dipengaruhi oleh jenis kelaminnya. Zhang et al. (2008) menyebutkan bahwa BL cempe jantan lebih tinggi jika dibandingkan dengan cempe betina. Hal tersebut disebabkan karena kecepatan pertumbuhan pra lahir cempe jantan lebih tinggi dibandingkan dengan cempe betina (Sutama, I. Ketut, 1995), dimana diketahui pada umumnya sekresi hormon pertumbuhan anak jantan lebih aktif daripada anak betina (Nalbandov, 1990).

Zhang et al.(2008) menyebutkan bahwa tahun pengamatan menunjukkan perbedaan yang signifikan pada BL keturunan. Dalam penelitian ini, BL cempe sangat beragam untuk setiap tahun (Tabel 2). Tingginya perbedaan BLpada masing-masing tahun ini bisa dijelaskan dari perubahan manajemen pemeliharaan yang dilakukan sehingga memengaruhi performa ternak baik anak, pejantan maupun induk kemudian berimbas pada BL anak.

\subsection{Pengaruh Dam Effectpada Berat Lahir}

Data hasil quality control digunakan dalam perhitungan dua model ANOVA, kemudian dibandingkan dengan prosedur $F$ test untuk mengetahui signifikansi adanya dam effect. Hasil perbandingan model ditampilkan pada Tabel 3.
Tabel 2. Faktor, jumlah data, rerata dan standar deviasi Berat Lahir

\begin{tabular}{|c|c|c|}
\hline Faktor & $\mathrm{n}$ & $\mathrm{BL}$ \\
\hline \multicolumn{3}{|l|}{ Pejantan } \\
\hline CC Jr & 23 & $3,15 \pm 0,71^{a}$ \\
\hline ER Jr & 20 & $3,13 \pm 0,54^{\mathrm{a}}$ \\
\hline RK & 94 & $3,07 \pm 0,69^{a b}$ \\
\hline GD & 118 & $3,04 \pm 0,66^{a b}$ \\
\hline BR & 95 & $3,04 \pm 0,67^{\mathrm{abc}}$ \\
\hline DA & 113 & $2,98 \pm 0,50^{\mathrm{abc}}$ \\
\hline$A D$ & 78 & $2,97 \pm 0,63^{\mathrm{abc}}$ \\
\hline TR & 55 & $2,97 \pm 0,54^{\mathrm{abc}}$ \\
\hline $\mathrm{CH} \mathrm{Jr}$ & 16 & $2,94 \pm 0,44^{\mathrm{abc}}$ \\
\hline $\mathrm{CH}$ & 109 & $2,92 \pm 0,70^{\mathrm{abc}}$ \\
\hline CC & 50 & $2,91 \pm 0,56^{\mathrm{abcd}}$ \\
\hline so & 131 & $2,88 \pm 0,66^{\mathrm{abcd}}$ \\
\hline WN & 16 & $2,87 \pm 0,67^{\text {abcd }}$ \\
\hline $\mathrm{ER}$ & 64 & $2.83 \pm 0.61^{\mathrm{bcd}}$ \\
\hline GD Jr & 12 & $2,77 \pm 0,43^{\mathrm{cd}}$ \\
\hline CS Jr & 7 & $2,64 \pm 0,56^{\mathrm{d}}$ \\
\hline \multicolumn{3}{|c|}{ Komposisi darah induk } \\
\hline $50 \%$ Boer (F1) & 853 & $2,97 \pm 0,63$ \\
\hline $75 \%$ Boer (F2) & 148 & $2,94 \pm 0,64$ \\
\hline \multicolumn{3}{|l|}{ Paritas } \\
\hline 1 & 577 & $2,87 \pm 0,60^{b}$ \\
\hline 2 & 314 & $3,11 \pm 0,65^{\mathrm{a}}$ \\
\hline 3 & 110 & $3,05 \pm 0,65^{a}$ \\
\hline \multicolumn{3}{|l|}{ Jenis kelamin } \\
\hline Jantan & 499 & $3,05 \pm 0,62^{\mathrm{a}}$ \\
\hline Betina & 502 & $2,88 \pm 0,62^{b}$ \\
\hline \multicolumn{3}{|l|}{ Tipe kelahiran } \\
\hline Tunggal & 426 & $3,32 \pm 0,66^{\mathrm{a}}$ \\
\hline Kembar & 575 & $2,70 \pm 0,45^{b}$ \\
\hline \multicolumn{3}{|l|}{$\begin{array}{l}\text { Tahun } \\
\text { pengamatan BL }\end{array}$} \\
\hline 2013 & 93 & $2,48 \pm 0,42^{d}$ \\
\hline 2014 & 409 & $3,13 \pm 0,64^{a}$ \\
\hline 2015 & 445 & $2,94 \pm 0,61^{b}$ \\
\hline 2016 & 54 & $2,76 \pm 0,34^{c}$ \\
\hline Total data & 1001 & $2,97 \pm 0,63$ \\
\hline Keterangan: & $\begin{array}{l}\text { ript } \\
\text { yans } \\
\text { an y }\end{array}$ & $\begin{array}{l}\text { berbeda } \\
\text { ma menunju } \\
\text { ignifikan }\end{array}$ \\
\hline
\end{tabular}

Hasil perbandingan menunjukkan adanya dam effect pada BL yang ditunjukkan oleh nilai $P<0,05$. Dapat dijelaskan lebih lanjut bahwa individu induk memberikan pengaruh yang berbeda terhadap BL. Induk sebagai individu memberikan pengaruh yang besar terhadap BL berkaitan dengan kemampuan masing-masing induk dalam menyediakan lingkungan uterus yang baik selama masa kebuntingan melalui pemenuhan nutrien untuk 
embrio(Szwaczkowski et al., 2006; Van Niekerk et al., 1996). Kekurangan nutrien pada masa kebuntingan akan menyebabkan pertumbuhan embrio kurang optimal yang kemudian memengaruhi BL (Bradford, 1972).

Tabel 3. Komparasi Model untuk Perhitungan Dam Effect

\begin{tabular}{cccc}
\hline \multirow{2}{*}{ Variabel } & \multicolumn{2}{c}{ Mean Square Error } & \multirow{2}{*}{ Nilai P } \\
\cline { 2 - 3 } & Model 1 & Model 2 & \\
\hline BL & 0,249 & 0,185 & $<0,001$ \\
\hline Kenn
\end{tabular}

Keterangan: Signifikansi perbedaan ditunjukkan dengan nilai $\mathrm{P}<0,05$

Ekspresi genetik induk ditampilkan sebagai pengaruh lingkungan bagi anaknya (dam effect) (Robison, 1981). Karenanya, sifat pertumbuhan ternak terutama mamalia mempunyai kompleksitas lebih terhadap pendugaan ragam genetiknya dimana efisiensi seleksi akan menurun apabila dam effects tidak dimasukkan ke dalam perhitungan estimasi parameter genetik pada program breeding. Hal tersebut menjelaskan bahwa pengaruh induk (dam effect) sangat besar pengaruhnya terhadap BL.

\section{KESIMPULAN}

Berdasarkan hasil komparasi Model 1 dan 2 , diperoleh adanya dam effect pada sifat BL. Hasil tersebut menjelaskan bahwa berat lahir anak yang digunakan sebagai kriteria seleksi tidak hanya dipengaruhi oleh faktor pejantan saja, melainkan juga dipengaruhi oleh faktor induk betina. Untuk itu, keberadaan dam effect tersebut akan lebih baik diperhitungkan dalam proses seleksi.

\section{DAFTAR PUSTAKA}

Al-Shorepy, S. A., Alhadrami, G. A., \& Abdulwahab, K. (2002). Genetic and phenotypic parameters for early growth traits in Emirati goat. Small Ruminant Research, 45(3), 217-223. https://doi.org/10.1016/S09214488(02)00110-4

Bradford, G. (1972). The role of maternal effects in animal breeding: VII. Maternal effects in sheep. Journal of Animal Science, 35(6), 1324-1334.

Casey, N. H., \& Van Niekerk, W. A. (1988). The boer goat. I. Origin, adaptability, performance testing, reproduction and milk production. Small Ruminant Research, 1(3), 291-302. https://doi.org/10.1016/09214488(88)90056-9

Devandra, C., \& Burns. (1994). Produksi Kambing di Daerah Tropis. Bandung: Penerbit ITB.

Elieser, S., Doloksaribu, M., Mahmilia, F., Tarigan, A., \& Romjali, E. (2004). Bobot Lahir Beberapa Genotipe Kambing Hasil Persilangan. In Seminar Nasional Teknologi Peternakan dan Veteriner 2004 (pp. 369-374).

Hardjosubroto, W. (1994). Aplikasi Pemuliaan Ternak di Lapangan. Jakarta: Gramedia Widiasarana Indonesia.

Mahmalia, F., Doloksaribu, M., \& Nasution, S. (2010). Pengaruh Faktor Non Genetik Terhadap Bobot Lahir Kambing Boer Pada Stasiun Percobaan Loka Penelitian Kambing Potong Sei Putih ( Effect Of Non-Genetic Factors On Birth Weight Of Boer Goat At Research Station For Goat Production , Sei Putih ). Seminar Nasional Teknologi Peternakan Dan Veteriner, 477-481.

Mandal, A., Neser, F. W. C., Rout, P. K., Roy, R., \& Notter, D. R. (2006). Estimation of direct and maternal (co)variance components for pre-weaning growth traits in Muzaffarnagari sheep. Livestock Science, 99, 79-89.

Nalbandov, A. V. (1990). Fisiologi Reproduksi pada Mamalia dan Unggas. Jakarta: UI Press.

Nasich, M. (2011). Produktivitas kambing hasil persilangan antara pejantan boer dengan induk lokal (pe) periode prasapih. J. Ternak Tropika, 12(1), 56-62.

Nurgiartiningsih, V. M. A. (2011). Evaluasi Genetik Pejantan Boer berdasarkan Performans Hasil Persilangannya dengan Kambing Lokal. Jurnal Ternak 
Tropika, 12, 82-88.

Ott, L., \& Longnecker, M. (2010). An Introduction to Statistics with Data Analysis. Belmont: Brooks/Cole, Cengage Learning.

Praharani, L. (2007). Pengaruh genetik maternal sifat pertumbuhan sapi Bali. Pengaruh Genetik Maternal Sifat Pertumbuhan Sapi Bali, 240-246.

Robison, O. W. (1981). The influence of maternal effects on the efficiency of selection; A review. Livestock Production Science, 8(2), 121-137. https://doi.org/10.1016/03016226(81)90016-6

Sutama, I. Ketut, et al. (1995). Productive and reproductive performances of young Ettawah-cross does. Indonesian Journal of Animal and Veterinary Sciences, 1(2), p.81-85.

https://doi.org/10.14334/jitv.v1i2.14
Szwaczkowski, T., Wojtowski, J., Stanislawka, A., \& Gut, A. (2006). Estimates of maternal genetic and permanent environmental effects in sheep. Archiv Tierzucht Dummerstorf, 49(36494), 186192.

Van Niekerk, M. M., Schoeman, S. J., Botha, M. E., \& Casey, N. (1996). Heritability estimates for pre-weaning growth traits in the Adelaide Boer goat flock. South African Journal of Animal Sciences, 26(1), 6-10.

Warwick, E. J., Astuti, J. W., \&Hardjosubroto, W. (1990). Pemuliaan Ternak. Yogyakarta: Gadjah Mada University Press.

Zhang, C., Yang, L., \& Shen, Z. (2008). Variance components and genetic parameters for weight and size at birth in the Boer goat. Livestock Science, 115(1), 73-79.

https://doi.org/10.1016/j.livsci.2007.06.00 8 